\title{
Establishment of Mass Spectrometric Fingerprints of Novel Synthetic Cholesteryl Neoglycolipids: The Presence of a Unique C-Glycoside Species During Electrospray Ionization and During Collision-Induced Dissociation Tandem Mass Spectrometry
}

\author{
Anas El-Aneed \\ Biochemistry Department, Memorial University of Newfoundland, St. John's, Newfoundland, Canada
}

Joseph Banoub* and Mariano Koen-Alonso

Department of Fisheries and Oceans, Science Branch, St. John's, Newfoundland, Canada

\begin{abstract}
Paul Boullanger and Dominique Lafont
Laboratoire de Chimie Organique 2, CNRS UMR 5181, Université Claude Bernard Lyon 1, Villeurbanne, France
\end{abstract}

\begin{abstract}
In this study we evaluated the fragmentation pattern of 16 novel amphiphilic neoglycolipid cholesteryl derivatives that can be efficiently used to increase cationic liposomal stability and to enhance gene transfer ability. These neoglycolipids bear different sugar moieties, such as D-glucosamine, $N$-acetyl-D-glucosamine, $N$-trideuterioacetyl-D-glucosamine, $\mathrm{N}$-acetyllactosamine, L-fucose, $\mathrm{N}$-allyloxycarbonyl-D-glucosamine, and some of their per-O-acetylated derivatives. Regardless of the structure of the tested neoglycolipid, QqToF-MS analysis using electrospray ionization (ESI) source showed abundant protonated $[\mathrm{M}+\mathrm{H}]^{+}$species. We also identified by both QqToF-MS and low-energy collision tandem mass spectrometry (CID-MS/MS) of the $[\mathrm{M}+\mathrm{H}]^{+}$ion, the presence of specific

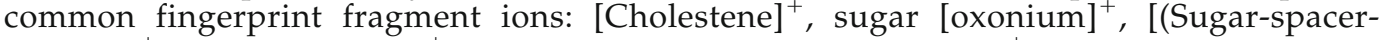
$\mathrm{OH})+\mathrm{H}]^{+}$, [oxonium $\left.-\mathrm{H}_{2} \mathrm{O}\right]^{+}$, and $[(\text {Cholesterol-spacer-OH })+\mathrm{H}]^{+}$. In addition, we observed a unique ion that could not be rationally explained by the expected fragmentation of these amphiphilic molecules. The structure of this ion was tentatively proposed with that of a $\mathrm{C}$-glycoside species formed by a chemical reaction between the sugar portion and the cholesterol. MS / MS analysis of this unique [C-glycoside $]^{+}$confirmed the validity of the proposed structure of this ion. The presence of an amino group at position C-2 and free hydroxyl groups of the sugar motif is crucial for the formation of a "reactive" sugar oxonium ion that can form the $\left[\mathrm{C}\right.$-glycoside ${ }^{+}$species. In summary, we precisely established the fragmentation patterns of the tested series of neoglycolipid cholesteryl derivatives and authenticated their structure as well; moreover, we speculated on the formation of a C-glycoside with the ESI source under atmospheric pressure and in the collision cell during MS/MS analysis. (J Am Soc Mass Spectrom 2007, 18, 294-310) ( 2007 American Society for Mass Spectrometry
\end{abstract}

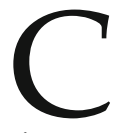

ationic liposomes are one of the most prevalent nonviral gene delivery systems used in gene therapy [1]. Their safety, simplicity of preparation, and high encapsulation capacity of foreign genetic

Published online November 7, 2006

Address reprint requests to Dr. Joseph H. Banoub, Fisheries and Oceans Canada, N.A.F.C., P.O. Box 5667, St. John's, Newfoundland, Canada A1C 5X1. E-mail: banoubjo@dfo-mpo.gc.ca

* Biochemistry Department, Memorial University of Newfoundland, St. John's, Newfoundland, Canada. materials make them an excellent candidate as an alternative to the immunogenic viral vectors that have been traditionally superior in terms of their gene transfer ability $[2,3]$. One major limitation of the usage of cationic liposomes is their tendency to aggregate and their rapid clearance in the circulatory system. Many modifications have been introduced to counter and prevent these drawbacks. Liposomal formulations bearing polyethylene glycol (i.e., PEG-liposomes) were, for example, introduced $[4,5]$ and have proven to signifi- 


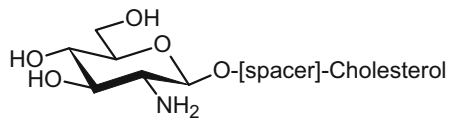

(1) spacer] $=$ none and $\left(\mathrm{CH}_{2} \mathrm{CH}_{2} \mathrm{O}\right)_{2}$

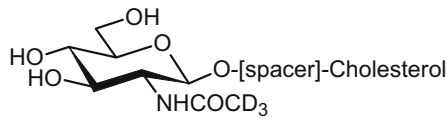

(3) $[$ spacer $]=\left(\mathrm{CH}_{2} \mathrm{CH}_{2} \mathrm{O}\right)_{3}$

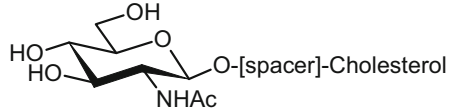

(2) [spacer] $=\left(\mathrm{CH}_{2} \mathrm{CH}_{2} \mathrm{O}\right)_{n}$ with $\mathrm{n}=0-3$, and

$\mathrm{CD}_{2} \mathrm{CH}_{2} \mathrm{OCH}_{2} \mathrm{CH}_{2} \mathrm{OCH}_{2} \mathrm{CH}_{2} \mathrm{O}$,

$\mathrm{CH}_{2} \mathrm{CH}_{2} \mathrm{OCH}_{2} \mathrm{CH}_{2} \mathrm{OCD}_{2} \mathrm{CH}_{2} \mathrm{O}$,

$\mathrm{CH}_{2} \mathrm{CH}_{2} \mathrm{OCD}_{2} \mathrm{CH}_{2} \mathrm{OCH}_{2} \mathrm{CH}_{2} \mathrm{O}$

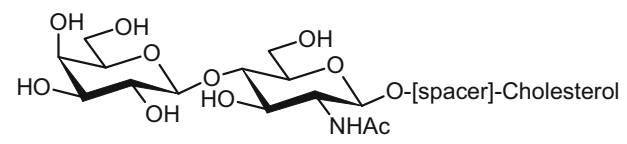

(4) [spacer] $=\left(\mathrm{CH}_{2} \mathrm{CH}_{2} \mathrm{O}\right)_{3}$

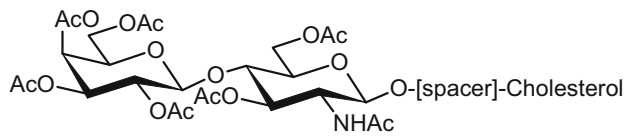

(4) [spacer] $=\left(\mathrm{CH}_{2} \mathrm{CH}_{2} \mathrm{O}\right)_{3}$, acetylated form

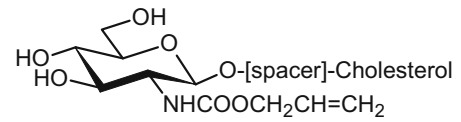

(6) $[$ spacer] $n=0,4$
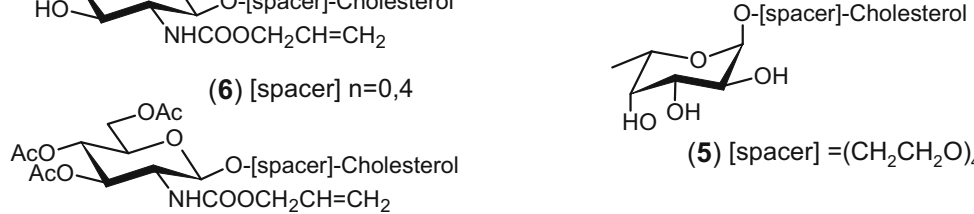

(5) $[$ spacer $]=\left(\mathrm{CH}_{2} \mathrm{CH}_{2} \mathrm{O}\right)_{4}$

(6) $[$ spacer] $=$ none, acetylated form

Scheme 1. The molecular structure of neoglycolipids.

cantly prolong the half-life of liposomal formulations by steric stabilization. More recently, synthetic neoglycolipids were tested as an alternative to PEG-liposomes, providing better formulations in terms of stability and gene transfer ability [6, 7].

Structural conformation and purity of synthetic neoglycolipids can be investigated with the aid of mass spectrometry [8,9]. In addition to structural studies, quality control and quality assurance of liposomal formulations are pharmaceutical necessities for the production of any therapeutically relevant liposomal-based gene carrier. Mass spectrometric analysis and fingerprint identification [through low-energy collision tandem mass spectrometry (CID-MS/MS) analysis] of different liposomal components can, with a great degree of sensitivity, assist in monitoring various steps in the production process as well as during any pharmacokinetic study [10, 11].

We recently reported, for the first time, the fragmentation pattern and the unique "in situ" formation of a C-glycoside species both within the electrospray ionization (ESI) interface and in the collision cell during the low-energy collision CID-MS/MS analysis of novel amphiphilic neoglycolipid cholesteryl derivatives containing $N$-acetyl-D-glucosamine [12]. In this study, only six neoglycolipids were evaluated, providing evidence for what we speculated was a C-glycosylation resulting from an ion-molecule reaction. This finding is of great interest in the field of carbohydrate chemistry because the occurrence of a C-glycosylation is, by far, more difficult than that of normal $\mathrm{O}$ - or $\mathrm{N}$-glycosylation reactions.

C-Glycoside chemistry has grown over the years and numerous published materials focus on the various methodologies of C-glycoside synthesis [13]. In addition, many $C$-glycoside analogues have been used for their therapeutic values such as anticancer vaccines [14, 15] and for protection against malaria as well as melanoma metastases [16]. The formation of aryl C-glycoside within the mass spectrometry is a novel finding that needs to be explored and may allow interesting simple gas-phase $\mathrm{C}$-glycoside reaction in contrast to tedious conventional bench-top chemistry.

To further explore the phenomenon of C-glycoside formation during mass spectrometric analysis, we synthesized a new series of cholesteryl neoglycolipids bearing various carbohydrate moieties and these are presented in Scheme 1. In addition, we performed the low-energy CID-MS/MS analysis of these series of novel synthetic neoglycolipids and, subsequently, identified the fingerprint fragment ions, which were common among different structures.

\section{Experimental}

\section{Synthesis of the Neoglycolipid Derivatives}

The synthesis of neoglycolipids 1-3 [17, 18], 4 [19], and $6[17,18]$ were performed as reported earlier. The 
syntheses of compounds 2 (with deuterated chains) and 5 [20] will be reported in due course. In these amphiphilic neoglycolipid cholesteryl derivatives, the cholesterol and the carbohydrate moieties were attached either by means of a polyethoxy variable spacer or with no spacer, as in the case of simple $O$-glycoside. The chosen carbohydrate portion was: D-glucosamine $\left(\mathrm{GlcNH}_{2}\right) \mathbf{1}$, $\mathrm{N}$-acetyl-D-glucosamine (GlcNAc) 2, N-trideuterioacetylD-glucosamine $\left(\mathrm{GlcNHCOCD}_{3}\right)$ 3, N-acetyllactosamine (LacNAc) 4, L-fucose (Fuc) 5, N-allyloxycarbonyl-Dglucosamine (GlcNAloc) 6, and the corresponding per$O$-acetylated derivatives of GlcNAloc and LacNAc carbohydrate residues (protected sugar species). The general molecular structure of these compounds is presented in Scheme 1. The total number of neoglycolipids investigated in this study was 16 .

\section{Electrospray Quadrupole Orthogonal Time-of-Flight Mass Spectrometry}

Mass spectra of the neoglycolipid derivatives were acquired in the positive ion mode. All experiments were performed with an API QSTAR XL MS/MS quadrupole orthogonal time-of-flight (QqToF-MS/MS) hybrid tandem mass spectrometer (Applied Biosystems, Foster City, CA). Traces of the neoglycolipid derivatives were dissolved in methanol or methanol/ dichloromethane $(1: 1)$. Sample solution was then infused into the mass spectrometer with an integrated Harvard syringe pump (Harvard Apparatus, Hollister, MA) at a rate of 5 $\mu \mathrm{L} / \mathrm{min}$ using the Turbo Ionspray Source. Formic acid was added to increase the formation of the $[\mathrm{M}+\mathrm{H}]^{+}$ protonated molecules.

\section{Influence of Declustering Potential (DP) and Focusing Potential (FP) on Ion Formation}

To study the influence of DP and FP on the ion count, the neoglycolipids were dissolved in methanol or methanol/ dichloromethane (1:1) such that the final concentration was $100 \mathrm{nmol} / \mathrm{mL}$. Variable values of DP and FP were generated using Microsoft Excel (Microsoft, Redmond, WA). Ion count of different ions was measured three times for each condition. All other instrument parameter were kept constant (ion source gas $1=25$; ion source gas $2=0$; curtain gas $=20$; temperature $=0$; and DP2 $=10$ ).

We randomly selected DP and FP values within the instruments' allowed ranges $(D P[-10,350]$ and $F P$ [0480]). The number of ion counts was performed for each combination of DP and FP values. Then, the correlation between ion counts and DP or FP values were evaluated using the Spearman rank correlation coefficient $\left(r_{\text {Spearman }}\right)$ [21]. After these initial test (see Results and Discussion), it was clear that only DP has influence on the ion count. Considering this result, we compared the shape of the relationship between ion count and DP obtained from the formation of the
C-glycoside with the ones obtained from the formation of other ions, $[\mathrm{M}+\mathrm{H}]^{+}$and $[(\text {Sugar-Spacer })+\mathrm{H}]^{+}$. These pairwise comparisons were made using the two samples Kolmogorov-Smirnov Test [21]. Ion counts from each experimental run were normalized to its maximum to ensure comparability among experiments (i.e., we want to compare the shape of these distributions, not their absolute magnitudes).

\section{Results and Discussion}

\section{QqToF-MS Analysis}

Regardless of the structure of the tested neoglycolipid, abundant protonated $[\mathrm{M}+\mathrm{H}]^{+}$species were observed during ESI-QqToF-MS analysis; in most cases, the sodiated $[\mathrm{M}+\mathrm{Na}]^{+}$along with the corresponding $[\mathrm{M}+\mathrm{K}]^{+}$ adduct ions were also formed. Formation of the protonated singly charged ion was enhanced by the addition of formic acid, whereas the series of fragment ions obtained in the ESI-MS were the same (i.e., with or without acid). QqToF-MS experiments also revealed the presence of a series of 1,2-cyclic sugar oxonium ion: [GlcNAc] ${ }^{+}$at $m / z$ 204.08, $\left[\mathrm{GlcNH}_{2}\right]^{+}$at $\mathrm{m} / \mathrm{z}$ 162.07, $\left[\mathrm{GlcNHCOCD}_{3}\right]^{+}$at $\mathrm{m} / \mathrm{z}$ 207.10, [Fuc] ${ }^{+}$at 147.01, [GlcNAloc] ${ }^{+}$at $m / z$ 246.07, [Lac$\mathrm{NAc}^{+}$at $m / z$ 366.11, and the corresponding per-O-acetylated species of GlcNAloc and LacNAc at $m / z 372.12$ and 618.20, respectively. Figure 1 represents the QqToF-MS spectra of four neoglycolipids bearing GlcNHCOCD GlcNAloc, GlcNH ${ }_{2}$, and GlcNAc (exact structures are shown within the figure) and illustrates the formation of the expected sugar [Oxonium] ${ }^{+}$ions. Note that this cyclic 1,2-oxonium ion is in fact an [oxzazolinium] ${ }^{+}$ion, in which the positive charge is delocalized on the $\mathrm{N}-\mathrm{C}-\mathrm{O}$ atoms of this 1,2-cylic structure, and this will be designated throughout this manuscript as the sugar [Oxonium ${ }^{+}$ion. In addition, the cholesteryl cation that bears a positive charge, speculated to be localized on $\mathrm{C}-3^{\prime}$, was formed, possibly by intact $\mathrm{C}-\mathrm{C}$ covalent bond cleavage and was assigned as the [Cholestene $]^{+}$ion observed at $\mathrm{m} / \mathrm{z}$ 369.35.

Scheme 2 is a general representation of the fragment ions observed during ESI-QqToF analysis of these series of neoglycolipids. In this schematic representation, and for the sake of simplicity, the sugar oxonium portion (the 1,2-oxazolinium ion) was illustrated as a glucosamine derivative. As can be seen from Figure 1 and Scheme 2, these neoglycolipds can fragment at either of the spacer's ends, producing the two diagnostic fragment ions designated as $[(\text { Sugar-spacer-OH })+\mathrm{H}]^{+}$ and/or $[(\text { Cholesterol-spacer-OH })+\mathrm{H}]^{+}$. Obviously, the length of the "Spacer-OH" corresponds with high accuracy to the tested neoglycolipids. Evidently, there were no "Spacer-OH" in the simple neoglycolipids with $O$-glycoside linkages and these were observed as protonated reducing sugars bearing the anomeric hydroxyl group. The occurrence of the $[(\text { Sugar-spacer-OH })+\mathrm{H}]^{+}$ species was more frequently formed during the analysis

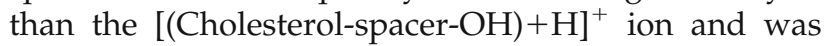



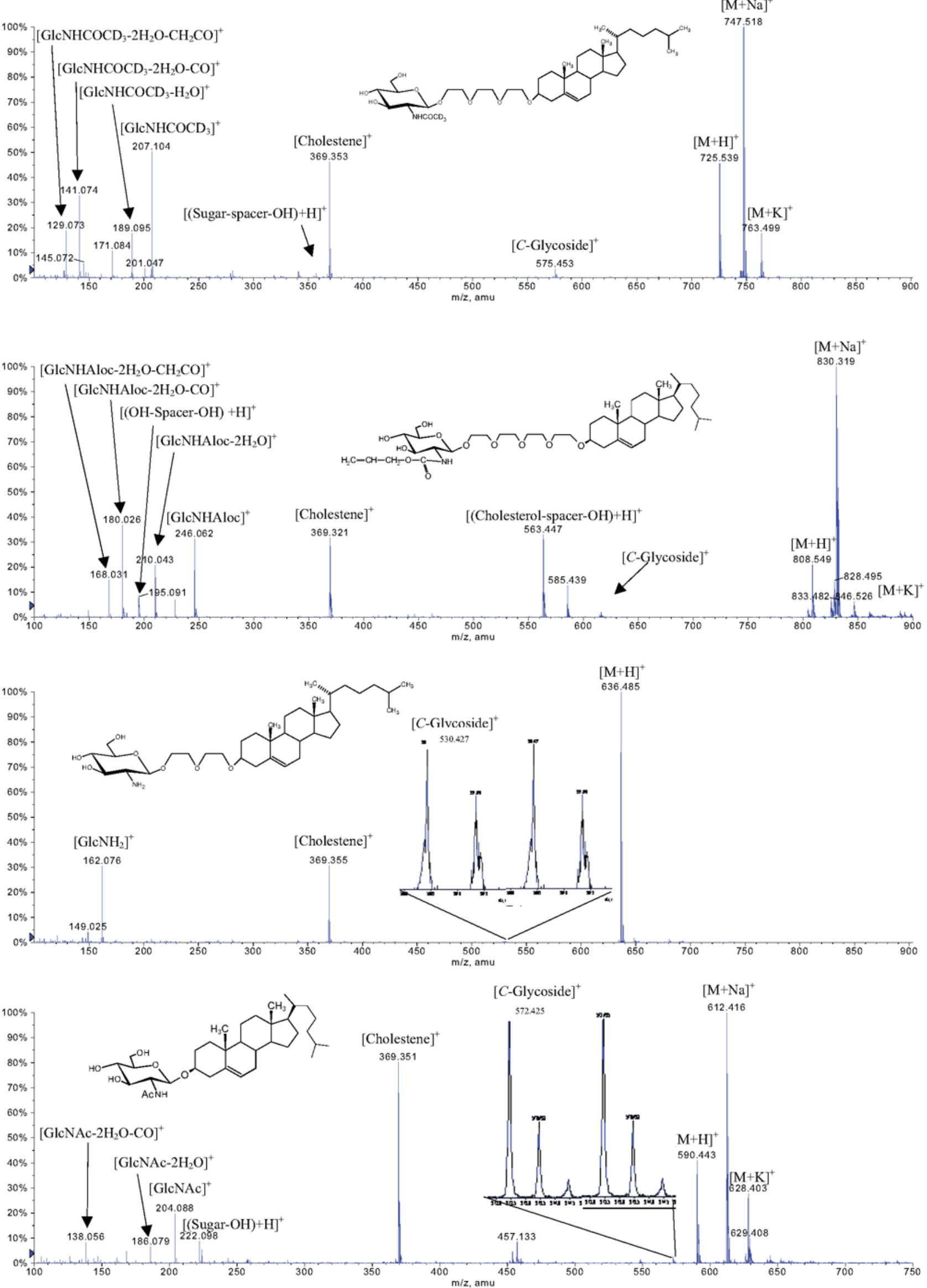

Figure 1. Four examples of positive QqToF-MS scans of different amphiphilic neoglycolipids (structure shown within the figure). 

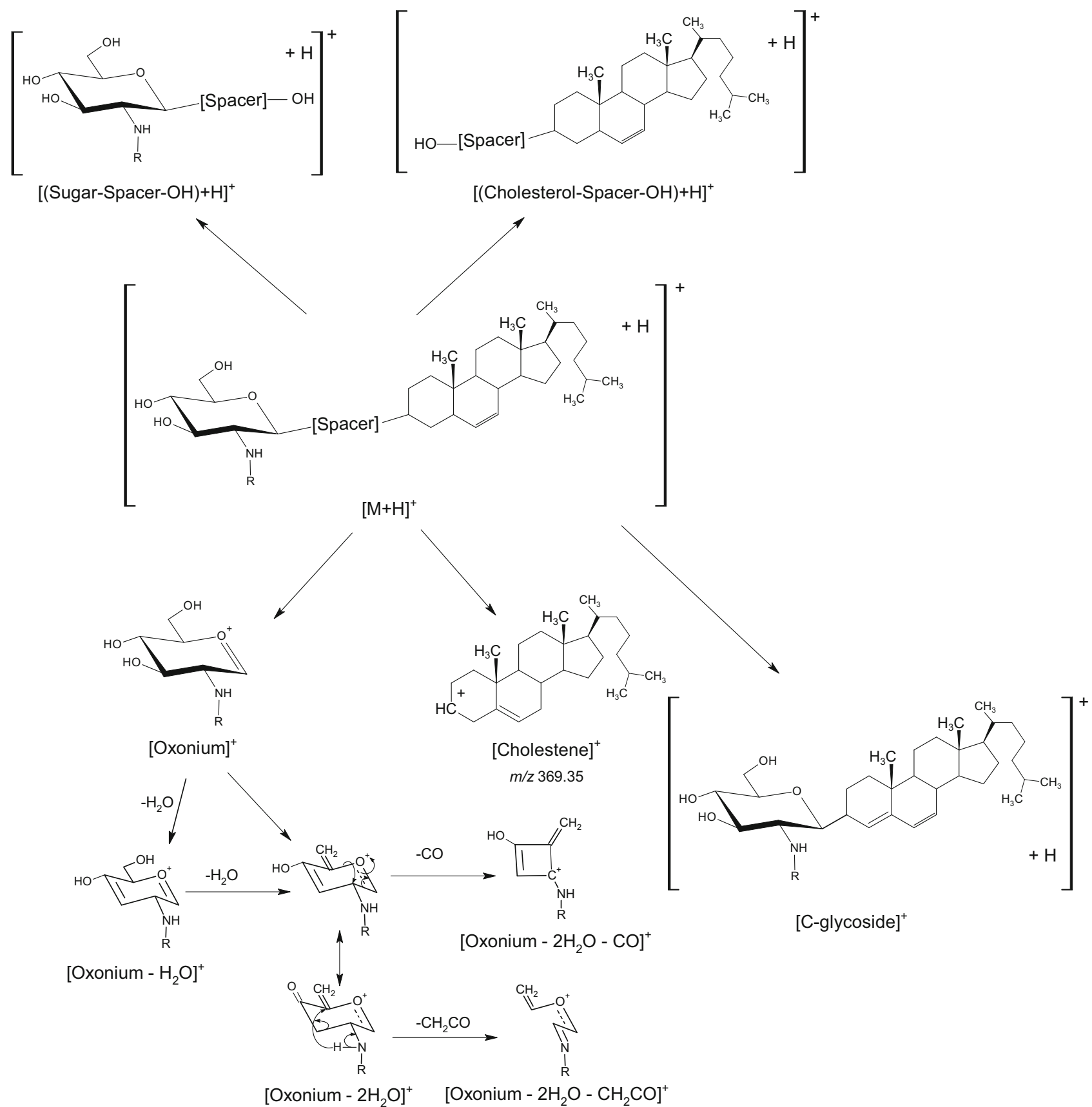

Scheme 2. General schematic representation of the proposed fragmentation pattern of the cholesteryl neoglycolipids observed in ToF-MS analysis. The sugar portion is illustrated as glucosamine derivative where $\mathrm{R}=\mathrm{H}, \mathrm{COCH}_{3}, \mathrm{COCD}_{3}$, or $\mathrm{COOCH}_{2} \mathrm{CH}=\mathrm{CH}_{2}$.

present in most of the studied neoglycolipids. The genesis of the $[(\text { Sugar-spacer-OH })+\mathrm{H}]^{+}$fragment ion was confirmed using four identical neoglycolipds that bear GlcNAc and a spacer of $\left(\mathrm{CH}_{2} \mathrm{CH}_{2} \mathrm{O}\right)_{3}$, which includes deuterated $\mathrm{CH}_{2}$ at varying positions of the chain. As expected, the nondeuterated species produced the $[(\text { Sugar-spacer-OH })+\mathrm{H}]^{+}$fragment ion at $\mathrm{m} / \mathrm{z}$ 354.17, whereas the $\mathrm{m} / \mathrm{z}$ value for the corresponding deuterated species was 356.18 (see Figure 2). Similarly, the presence of $\mathrm{GlNHHCOCD}_{3}$ instead of GlcNAc resulted, as ex- pected, in a shift in the $\mathrm{m} / \mathrm{z}$ value of the [(Sugar-spacer$\mathrm{OH})+\mathrm{H}]^{+}$ion from $\mathrm{m} / \mathrm{z} 354.17$ Th to $\mathrm{m} / \mathrm{z} 357.19$ Th (see Figure 2).

Additional elimination products, originating from the sugar [Oxonium] ${ }^{+}$ions, were also observed. These can be summarized as ions formed by the expected loss of one or two water molecules designated as [Oxonium$\left.\mathrm{H}_{2} \mathrm{O}\right]^{+}$and [Oxonium- $\left.2 \mathrm{H}_{2} \mathrm{O}\right]^{+}$. The subsequent elimination of $\mathrm{CO}$ and $\mathrm{CH}_{2} \mathrm{CO}$ from these product ions was also noted, forming the ions assigned as [Oxonium- 


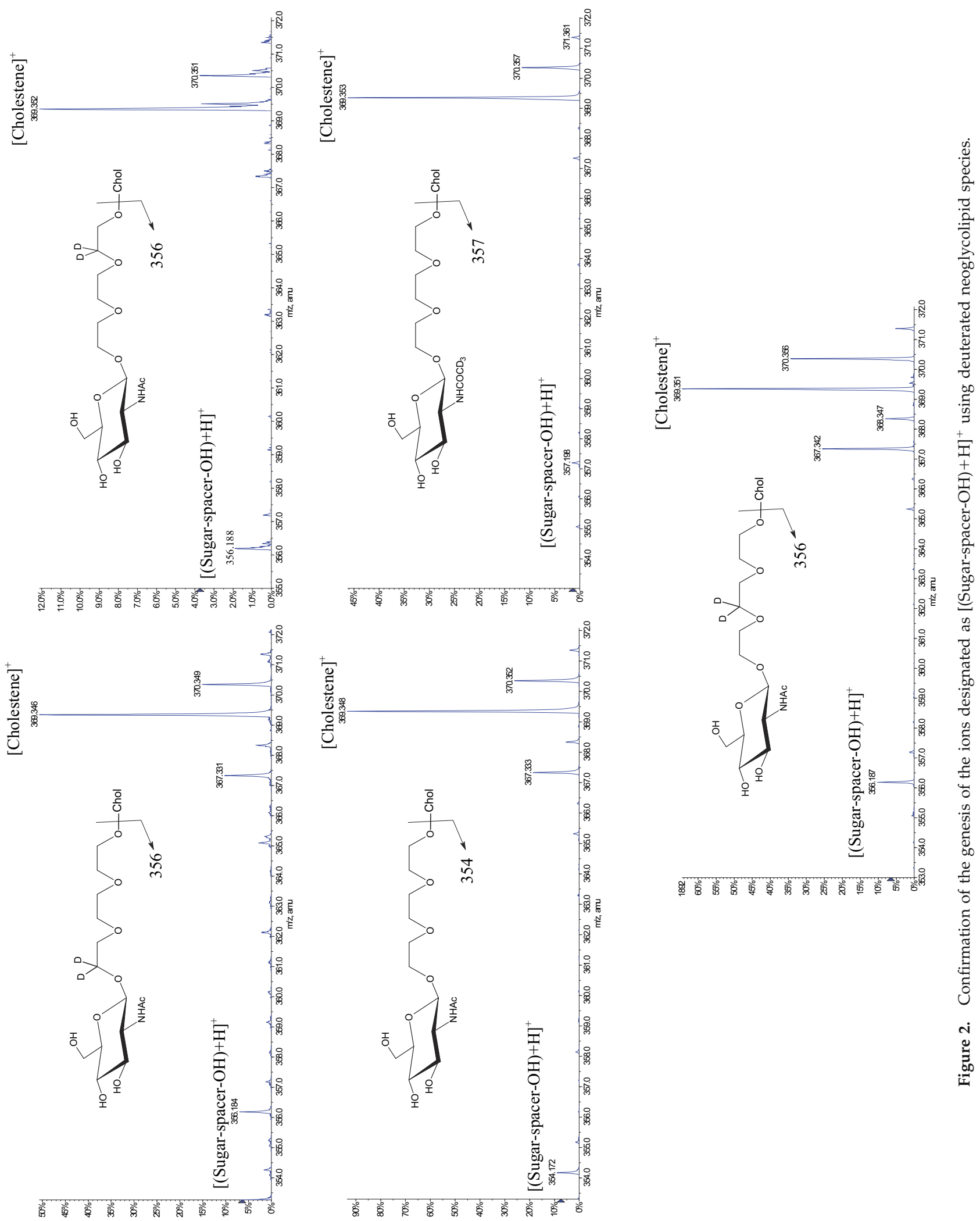


$\left.2 \mathrm{H}_{2} \mathrm{O}-\mathrm{CO}\right]^{+}$and [Oxonium- $\left.2 \mathrm{H}_{2} \mathrm{O}-\mathrm{CH}_{2} \mathrm{CO}\right]^{+}$. Figure 1 and Scheme 2 show the proposed mechanism of these losses.

Such elimination products were absent in the case of the sugar [Oxonium] ${ }^{+}$ions of the per-O-acetylated neoglycolipids. Instead, elimination products that correspond to [Oxonium-HOAc] ${ }^{+},[\mathrm{Oxonium}-2 \mathrm{HOAc}]^{+}$, and $\left[\right.$ Oxonium-3HOAc] ${ }^{+}$were observed (data not shown). The confirmation of the proposed structure of the various ions observed in the QqToF-MS was accomplished by CID-MS/MS analysis, as described below.

\section{Low-Energy Collision-Induced Dissociation Tandem Mass Spectrometric Analysis (CID-MS/MS)}

The discussion in this section will be divided based on the presence or absence of the acetylated hydroxyl groups within the sugar portion (i.e., protected versus nonprotected species).

\section{CID-MS/MS Analysis of the Precursor Protonated Molecules of the Nonprotected Neoglycolipids}

Table 1 summarizes the fragment ions observed in the CID-MS/MS analysis of the precursor protonated molecules $[\mathrm{M}+\mathrm{H}]^{+}$of some of the amphiphilic neoglycolipids. In this table, a comparison was made between nine neoglycolipids that bear different sugars: either a linker with different lengths of polyethoxy spacer or a simple O-glycoside linkage. The coding of the compounds in this table was based on the assigned number in Scheme $\mathbf{1}$ and the nature of the spacer.

As can be seen from Table 1, a general fragmentation pattern that is in agreement with Scheme 2 was observed.

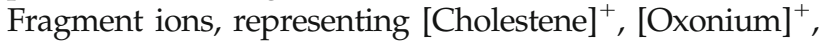
$[(\text { Sugar-spacer-OH })+\mathrm{H}]^{+}$, and $[($Cholesterol-spacer$\mathrm{OH})+\mathrm{H}]^{+}$were identified. Figure 3 shows the CIDMS/MS spectra of three neoglycolipids bearing LacNAc and GlcNAc sugar moieties. It is noteworthy to mention that in the case of the simple cholesteryl 2-acetamido $\beta$-D-glycopyranoside and the 2-amino- $\beta$-D-glycopyranoside (O-glycosides), in which the glycosyl portion was attached to the cholesterol aglycone through a 1,2-trans- $\beta-$ D-glycosidic bond; we obtained the protonated reducing sugar moiety $[(\mathrm{Sugar}-\mathrm{OH})+\mathrm{H}]^{+}$ion, whereas the $[$(Sugarspacer-OH) $+\mathrm{H}]^{+}$fragment ion was evidently missing (see Figure 3a).

As expected, elimination product ions derived from the sugar 1,2-cyclic [Oxonium] ${ }^{+}$species were also observed and were similar to those obtained by conventional single-stage QqToF-MS analysis (Scheme 2). The general fragmentation pattern observed in the CIDMS/MS spectra (Table 1) suggested that the ions obtained in the one-stage QqToF-MS (Figure 1) are indeed fragments that originate from the protonated species of these neoglycolipids, rather than being separate species. This was supported by the fact that the "in source"

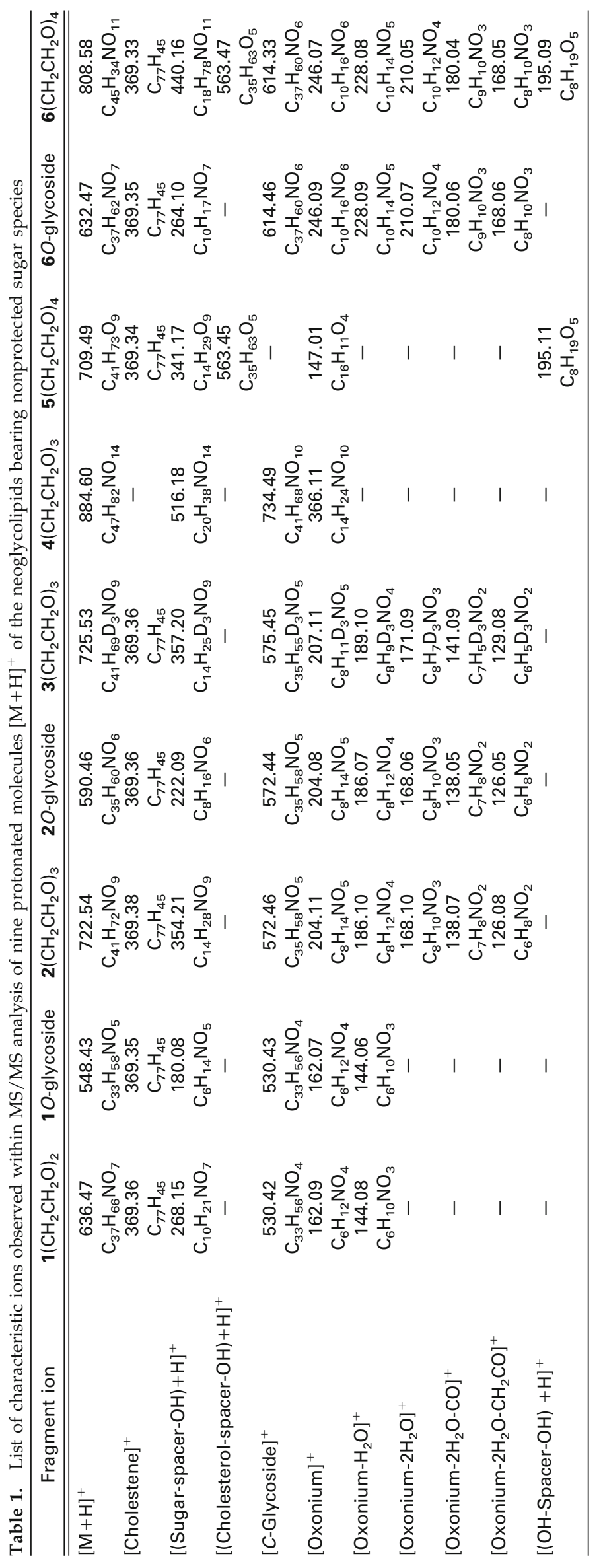



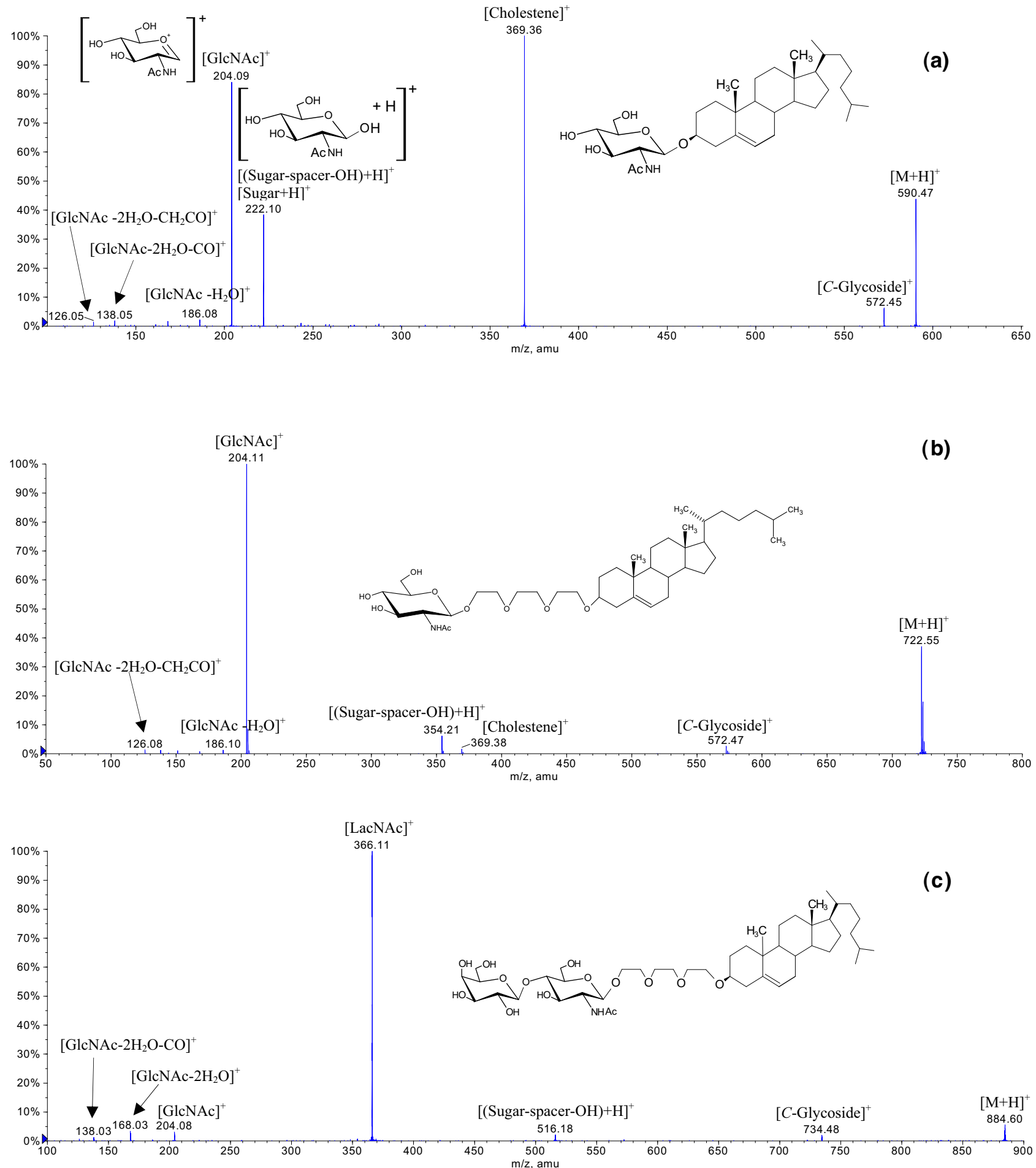

Figure 3. MS/ MS experiments of neoglycolipids bearing (a) GlcNAc linked to the cholesterol portion by O-Glycoside; (b) GlcNAc linked to the cholesterol portion by $\left(\mathrm{CH}_{2} \mathrm{CH}_{2} \mathrm{O}\right)_{3}$ spacer; and (c) LacNAc linked to the cholesterol portion by $\left(\mathrm{CH}_{2} \mathrm{CH}_{2} \mathrm{O}\right)_{3}$ spacer.

fragmentation was significantly repressed when manipulating the mass spectrometry parameters, that is, reducing the Declustering Potential (DP). It was also observed that the presence of the [(Cholesterol-spacer$\mathrm{OH})+\mathrm{H}]^{+}$and $[(\mathrm{OH}-\text { Spacer-OH })+\mathrm{H}]^{+}$fragment ions were only associated with the neoglycolipids bearing a polyethoxy spacer of $\left(\mathrm{CH}_{2} \mathrm{CH}_{2} \mathrm{O}\right)_{4}$ (Table 1, Figure $3 \mathrm{~b}$ ).
In addition to the expected fragment ions, the recognized formation of the unique $[C-G l y c o s i d e]^{+}$ion was observed during the CID-MS/MS only when the neoglycolipids contained a 1,2-participating group, with the exception of L-fucose. In fact, this ion was also present in the conventional one-stage QqToF-MS; careful examination of the spectra shows that the [C- 
Glycoside $]^{+}$ion was also formed during ESI ionization and it was not simply an "impurity," as was initially speculated when examining the QqToF-MS spectra (refer to Figure 1). We hypothesized that this ion results from a unique ion-molecule reaction between the neutral cholesterol on the sugar portion of the 1,2-cyclic oxonium ion species, from the $\beta$-face of this ion, thus producing the 1,2-trans-C-Glycoside: specifically an electrophilic addition of the conjugated diene of the cholesta-3,5-diene neutral molecule, on the electrondeficient 1,2-cyclic [oxonium] ${ }^{+}$ion (Lewis acid). The presence of this [C-Glycoside] $]^{+}$species was originally noticed in the MS/MS analysis of six neoglycolipid cholesteryl derivatives containing $\mathrm{N}$-acetyl-D-glucosamine and was confirmed by MS/MS (referred to as quasi-MS3 analysis of this unique ion [12]. Further discussion on the structure and formation of this ion using the various neoglycolipids evaluated in this study will be presented in the following sections.

Finally, the presence of LacNAc $(\beta$-D-Galp- $(1 \rightarrow 4)$-DGlc $p$ NAc) resulted in the formation of additional sugar fragment ions beside those presented in Table 1 (Figure $3 \mathrm{C}$ ). These ions were formed from the diagnostic [LacNAc] $^{+}$ion observed at $m / z 366.11$ [Oxonium] ${ }^{+}$) and include the [GlcNAc] ${ }^{+}$ion at $\mathrm{m} / \mathrm{z} 204.08$, the [GlcNAc$\left.2 \mathrm{H}_{2} \mathrm{O}\right]^{+}$ion at $\mathrm{m} / \mathrm{z} 186.04$, and the [GlcNAc- $2 \mathrm{H}_{2} \mathrm{O}-$ $\mathrm{CO}]^{+}$ion at $\mathrm{m} / \mathrm{z} 138.03$ (all derived from the reducing end of the disaccharide). The presence of these additional fragments is expected and they serve as diagnostic product ions confirming the structure of this neoglycolipid.

To verify the authenticity of the fragment ions assigned based on the conventional single-stage QqToF-MS analysis and on the CID-MS/MS experiments of the precursor protonated species $[\mathrm{M}+\mathrm{H}]^{+}$, additional CID-MS/MS analyses were obtained by increasing the "in source" fragmentation (also called "in nozzle" fragmentation), which can be enhanced and optimized for each tested species through manipulation of the Declustering Potential (DP) and the Focusing Potential (FP) values within the ionization source (i.e., optimum potentials for each precursor ion, in terms of ion count and S/N ratio). Both DP and FP are electrical voltages that have the greatest effects on the extent of the fragmentation within the orifice-skimmer region of the ESI source of the QStar XL hybrid tandem mass spectrometer.

Figure 4 represents the low-energy collision CIDMS/MS spectra of the extracted protonated molecule $[\mathrm{M}+\mathrm{H}]^{+}$of neoglycolipid 6 (Scheme 1) bearing $\left(\mathrm{CH}_{2} \mathrm{CH}_{2} \mathrm{O}\right)_{4}$ as a spacer (Figure 4a) as well as the CID-MS/MS of the extracted precursors: [(Cholesterolspacer-OH $)+\mathrm{H}^{+}$(Figure $\left.4 \mathrm{~b}\right)$ and the $[(\mathrm{OH}-\mathrm{Spacer}-$ $\mathrm{OH})+\mathrm{H}]^{+}$fragment ions (Figure 4c). As can be seen in Figure 4, the CID-MS/MS analysis of the $[\mathrm{M}+\mathrm{H}]^{+}$ ion followed the same pattern as discussed earlier and shown in Scheme 2 and Table 1. However, the CID-MS/MS of the $[(\text { Cholesterol-spacer-OH })+\mathrm{H}]^{+}$ species at 563.47 produced two major product ions corresponding to [Cholestene] ${ }^{+}$at $\mathrm{m} / \mathrm{z} 369.33$ and the $\left[\left(\mathrm{HO}-\left(\mathrm{CH}_{2} \mathrm{CH}_{2} \mathrm{O}\right)_{3}-\mathrm{OH}\right)+\mathrm{H}\right]^{+}$at $\mathrm{m} / z$ 195.09. Similarly, the CID-MS/MS of the [(HO$\left.\left.\left(\mathrm{CH}_{2} \mathrm{CH}_{2} \mathrm{O}\right)_{3}-\mathrm{OH}\right)+\mathrm{H}\right]^{+}$ion at 195.09 produced product ions corresponding to the proposed structure of this ion (see Figure 4C). It showed distinctive, consecutive losses of water molecules followed by elimination of an acetylene species $(\mathrm{CH} \equiv \mathrm{CH})$.

Similar analyses were also conducted on all the ions presented in Table 1, confirming their proposed structures, and these findings established the universal fragmentation pattern illustrated in Scheme 2.

\section{Formation of [C-Glycoside $]^{+}$}

As shown in Table 1 and Figure 3, the [C-Glycoside] ${ }^{+}$ species were observed first during the MS/MS experiment within the collision cell of the tandem mass spectrometer. However, this ion was also present in the one-stage ESI-QqToF experiment (see Figure 1). The formation of this unique ion cannot be explained based on the molecular structure of these novel synthetic neoglycolipids (Scheme1). To confirm the proposed structure of this ion, CID-MS/MS was performed on the isolated [C-glycoside $]^{+}$. This analysis tentatively showed that this ion can undergo two concerted cleavages, which occur simultaneously from the precursor

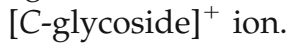

The first involves the elimination of the axial H-2 hydrogen of the sugar moiety, with consecutive rupture and migration of the anomeric $\mathrm{C}-1-\mathrm{C}-3^{\prime}$ bond and the consequent formation of the neutral fragment $2-\mathrm{N}$ acetyl-2-deoxy-D-glucal. This is followed by formation of the C $-3^{\prime}-\mathrm{C}-4^{\prime}$ double bond and migration of the endocyclic C $-4^{\prime}-\mathrm{C}-5^{\prime}$ double bond, to afford the protonated cholest3,5-diene molecule assigned as [Cholesta-3,5-diene $+\mathrm{H}]^{+}$ at $m / z 369.35$.

The second mechanism tentatively suggests the participation of the lone pair of electrons on the sugar ring oxygen, to afford the stable sugar 1,2-oxonium ion [Oxonium $^{+}$, followed by an identical rupture of the anomeric $\mathrm{C}-1-\mathrm{C}-3^{\prime}$ bond and migration of the double bonds, to produce the neutral choles-3,5-diene molecule. Figure 5 shows the CID-MS/MS of two

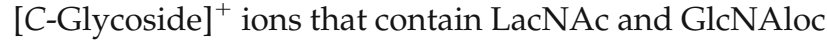
[extracted from the neoglycolipids 4 and 2, containing the $\left(\mathrm{OCH}_{2} \mathrm{CH}_{2}\right)_{3}$ spacer or simple $\mathrm{O}$-glycoside, respectively] and illustrates clearly the presence of [Cholesta3,5-diene $+\mathrm{H}]^{+}$at $\mathrm{m} / \mathrm{z} 369.35$ and [LacNAc] $^{+}$at $\mathrm{m} / \mathrm{z}$ 366.13 and [GlcNAc] ${ }^{+}$at $\mathrm{m} / \mathrm{z}$ 204.08. Elimination products of the sugar [Oxonium] ${ }^{+}$were also present in this MS/MS analysis. This MS/MS analysis authenticated the proposed structure of the [C-Glycoside $]^{+}$ion.

To explain the rationale beyond the formation of the $[C \text {-glycoside }]^{+}$ion, we proposed that a unique ionmolecule reaction occurs in the collision cell and within the ESI interface of the turbo ion spray source. It was postulated that the parent $[\mathrm{M}+\mathrm{H}]^{+}$ion of the complete neoglycolipid molecule undergoes covalent bond cleav- 

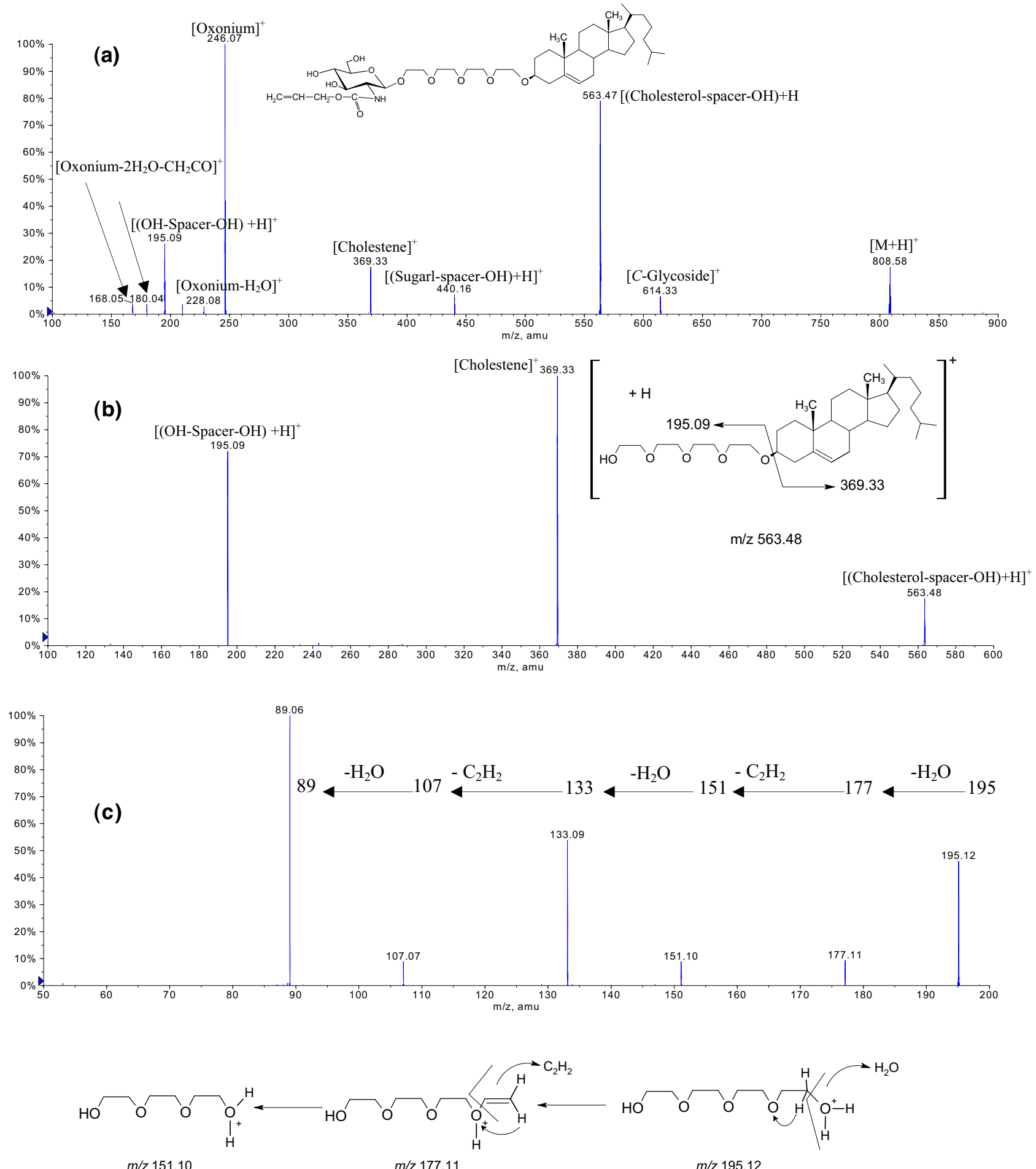

Figure 4. (a) MS/MS (MS [2] scan of neoglycolipid bearing GlcNAloc linked to the cholesterol portion by $\left(\mathrm{CH}_{2} \mathrm{CH}_{2} \mathrm{O}\right)_{4}$ spacer. (b) MS/MS of the fragment ion designated as [(Cholesterol-spacer$\mathrm{OH})+\mathrm{H}]^{+}$. (c) MS/MS of the fragment ion designated as $[(\mathrm{OH}-\mathrm{Spacer}-\mathrm{OH})+\mathrm{H}]^{+}$.

ages, producing the 1,2-cyclic sugar [Oxonium] $]^{+}$ion as well as the neutral cholesta-3,5-diene. This neutral molecule by migration of the conjugated double bond, attached itself on the 1,2-[oxonium] ${ }^{+}$ion, which is considered to be the electrophilic center. This addition is initiated by the loss of an $\alpha$-hydrogen atom, with respect to the double bond of the cholesta-3,5-diene portion, followed by attack on the positive charge that is delocalized on $\mathrm{N}-\mathrm{C}-\mathrm{O}$ atoms of the 1,2-cyclic [oxazolinium] $^{+}$ion, on the anomeric position, producing the ion designated as the $\left[C\right.$-Glycoside ${ }^{+}$(see Scheme $\mathbf{3 a}$ and $\mathbf{b}$ for details). The presence of the amino 

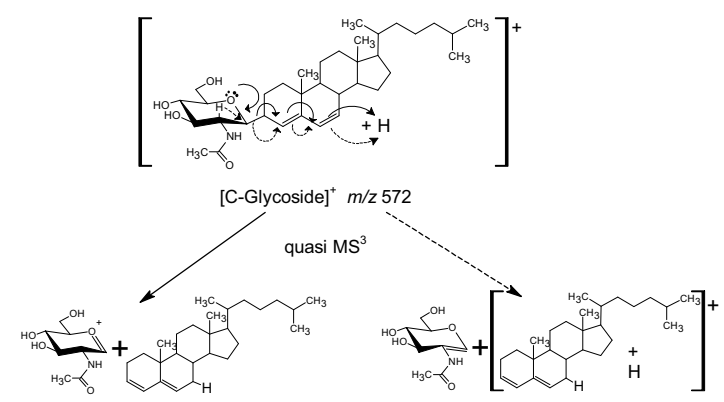

$m / z 204$

$m / z 369$
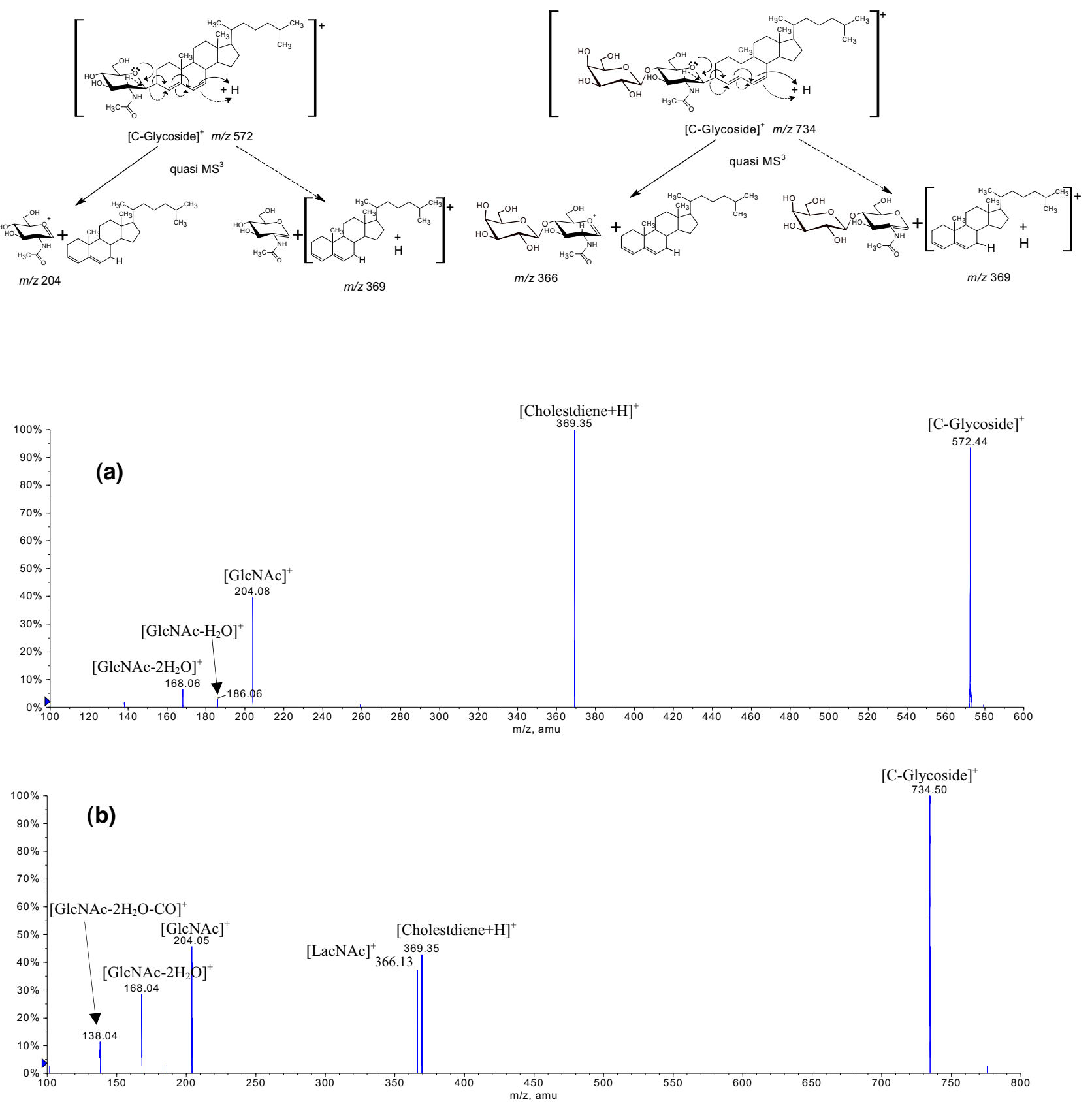

Figure 5. MS/MS of the ion identified as $[\mathrm{C} \text {-glycoside }]^{+}$, extracted from the neoglycolipids bearing (a) GlcNAc and linked to the cholesterol through O-glycoside linkage and (b) the LacNAc and linked the cholesterol through $\left(\mathrm{CH}_{2} \mathrm{CH}_{2}\right)_{3}$ spacer.

group at position C-2 of the sugar residue enhances the formation of a more "reactive species." This species is called in the case of the C-2 acetamido group, the 1,2-cyclic oxazolinium, whereas in the case of the 2-amino group it is called the "1,2-cyclic-aziridinium." Both oxonium ions containing a delocalized positive charge and thus are electron acceptors (also called Lewis acids).

In the event that the glycosyl portion of the neoglycolipid, did not bear a participating group at position $\mathrm{C}-2$, the formation of the [C-Glycoside $]^{+}$was absent, as in the case of neoglycolipid bearing the Fuc sugar
(Table 1). Despite the presence of the $[\mathrm{Fuc}]^{+}$oxonium ion at $m / z 147.01$, this ion failed to react with the neutral cholesta-3,5-diene molecule because it lacks the participating group at position C-2 (and thus does not form the reactive 1,2-cyclic oxonium ion) and, as a result, cannot form the corresponding ion [C-Glycoside ${ }^{+}$ (Scheme 3c).

As can be seen from Scheme 3 and Figure 5, we opted to illustrate that the tentative $[\mathrm{C} \text {-Glycoside }]^{+}$ions were produced by the formation of a C-1-C-3' covalent bond between the sugar and the cholesterol portions. However, the presence of another [C-Glycoside ${ }^{+}$ 


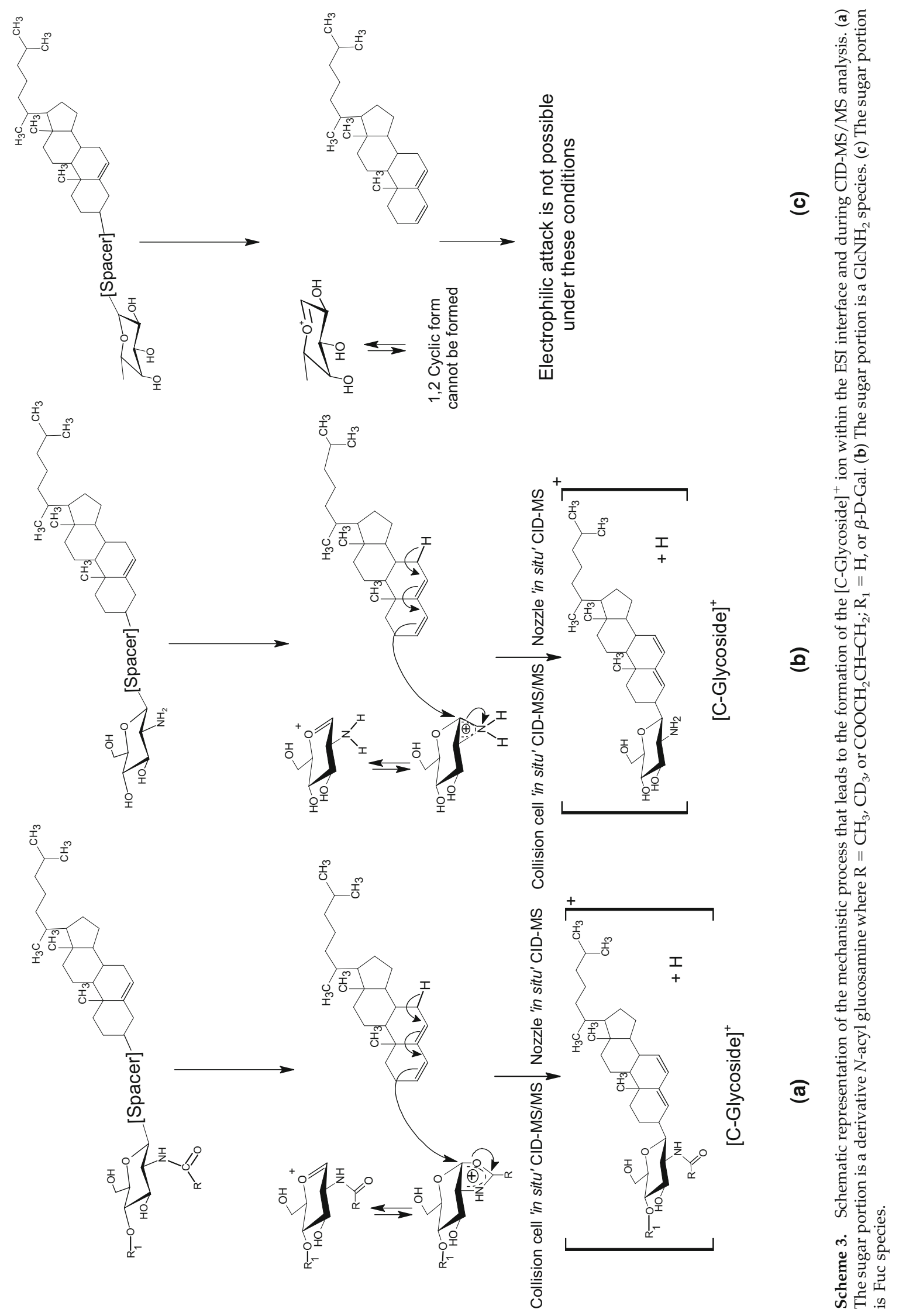



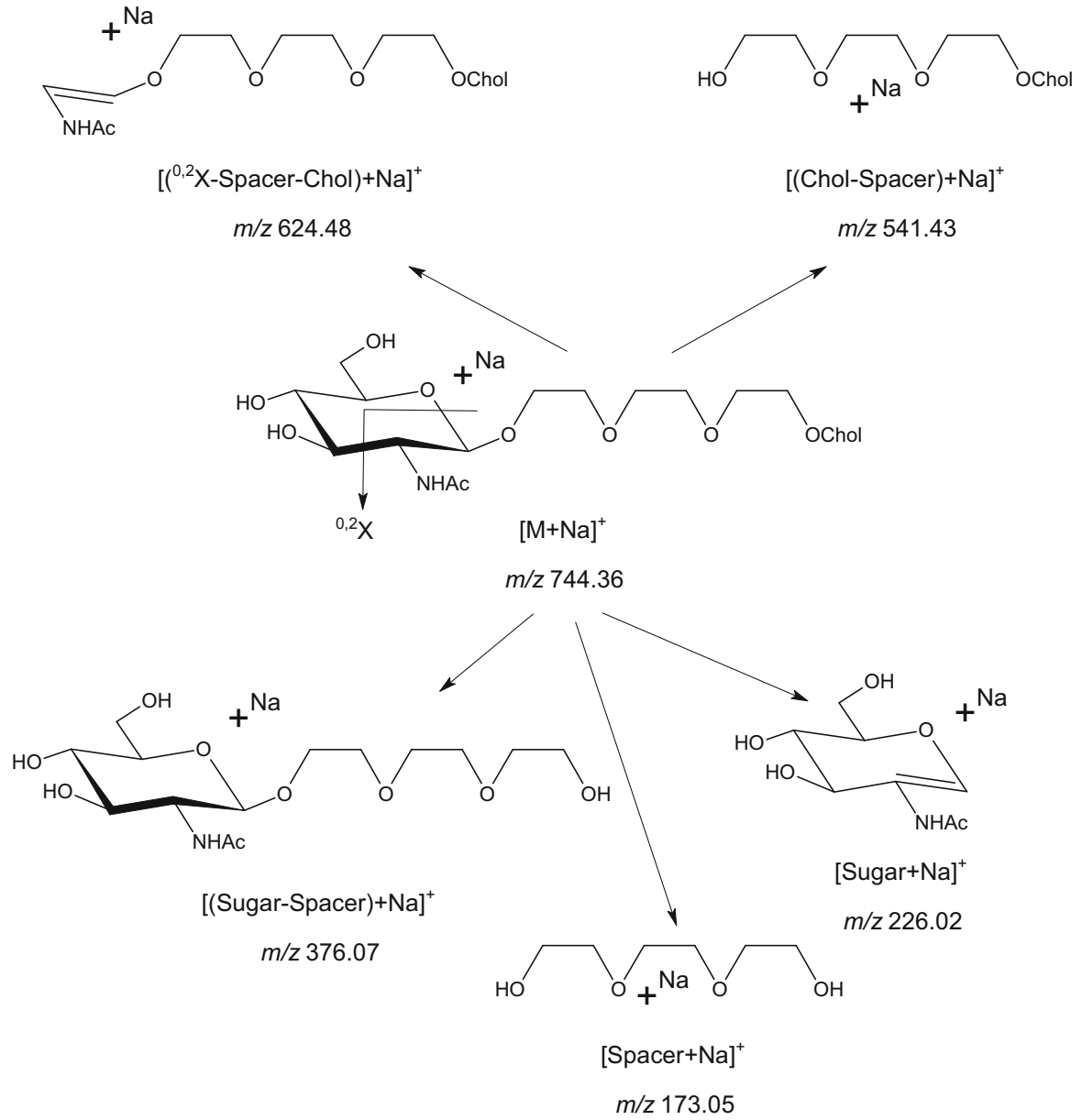

Scheme 4. The proposed fragmentation pattern of the $[\mathrm{M}+\mathrm{Na}]^{+}$of the neoglycolipid bearing GlcNAc with a $\left(\mathrm{CH}_{2} \mathrm{CH}_{2} \mathrm{O}\right)_{3}$ spacer.

species that carry the C-1-C-5' covalent bond cannot be excluded by the same mechanism, although it is improbable because of the potential steric hindrance of this latter $C$-glycoside. Needless to say, there is no way to tell for sure whether the formed $C$-glycoside possesses the structure we proposed, wherever it has the $\beta$-D-or $\alpha$-D-configurations, whereas it has an anomeric mixture of both, and/or even may be a cyclic 1,2orthoester carbohydrate derivative type in which the C-cholesteryl aglycone would attack the central carbon atom of the positively charged 1,2-oxazolinium ion. This latter 1,2 cyclic $C$-orthoester is very unlikely to be formed, given that it will rearrange instantaneously in the presence of traces of acid into the corresponding proposed C-glycoside.

This is beyond the scope of this article and cannot be verified with the present instrumentation. Nevertheless, the structure we propose has tentatively been attributed to the $\beta$-D-configuration that is, without doubt, the preferred configuration and the more thermodynamically stable [22].

An argument in favor of our proposal is that the $\mathrm{C}$-glycoside formation was found to be concentration dependent. When the CID-MS/MS of the precursor protonated molecule $[\mathrm{M}+\mathrm{H}]^{+}$was extracted from a more concentrated solution, the comparative abundance of the $[C \text {-glycoside }]^{+}$species was augmented relative to the intensities of the other product ions.

In addition to the absence of the [C-Glycoside $]^{+}$in the case of Fuc-derived neoglycolipids, this ion was also absent in the low-energy CID-MS/MS analysis of all the sodiated adducts $[\mathrm{M}+\mathrm{Na}]^{+}$of the neoglycolipid series evaluated in this study. For illustration purpose, Scheme 4 represents the fragmentation pattern of the product ion scan of the $[\mathrm{M}+\mathrm{Na}]^{+}$, isolated from the neoglycolipid designated as 3 , containing the spacer $\left(\mathrm{CH}_{2} \mathrm{CH}_{2} \mathrm{O}\right)_{3}$. The fact that both [Oxonium] ${ }^{+}$and [Cholestene] ${ }^{+}$ions were absent in the MS/MS of the $[\mathrm{M}+\mathrm{Na}]^{+}$suggests that this adduct breaks in different fashion than the one observed with $[\mathrm{M}+\mathrm{H}]^{+}$and does not form the reactive species that can result in the formation of the $C$-glycoside bond. All the fragment ions were actually sodiated species and included a fragment ion that is generated from inner sugar breakage, that is, ${ }^{0,2} \mathrm{X}$. Such inner sugar fragments are common and widely observed in glycoconjugate analysis [23, 24], and it was observed 

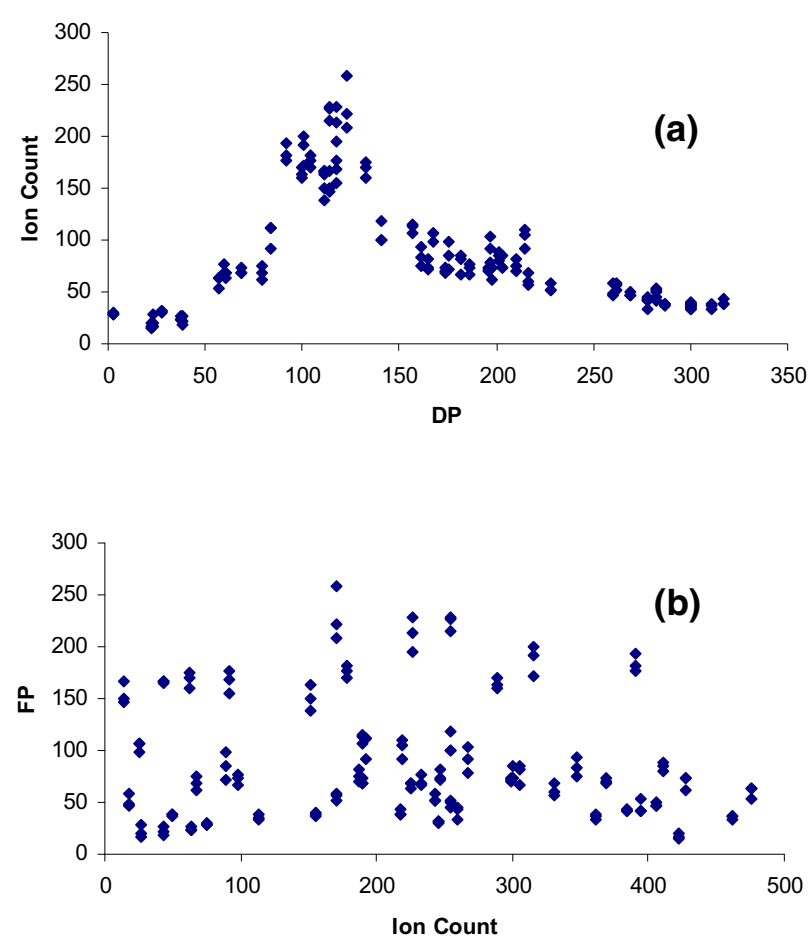

Figure 6. The relationship between $[\mathrm{C} \text {-glycoside }]^{+}$ion count and (a) DP values; (b) FP values.

in our study of the $[\mathrm{M}+\mathrm{H}]^{+}$, that is, the ion designated [Oxonium $\left.-2 \mathrm{H}_{2} \mathrm{O}-\mathrm{CH}_{2} \mathrm{CO}\right]^{+}$(see Scheme 2).

\section{Influence of DP and FP on the Formation of C-Glycoside}

Both DP and FP are electrical voltages that have the greatest effect on the extent of fragmentation within the orifice-skimmer region of the ESI source. CGlycoside ion formation was significantly correlated with the DP (Spearman's correlation coefficient, $P=$

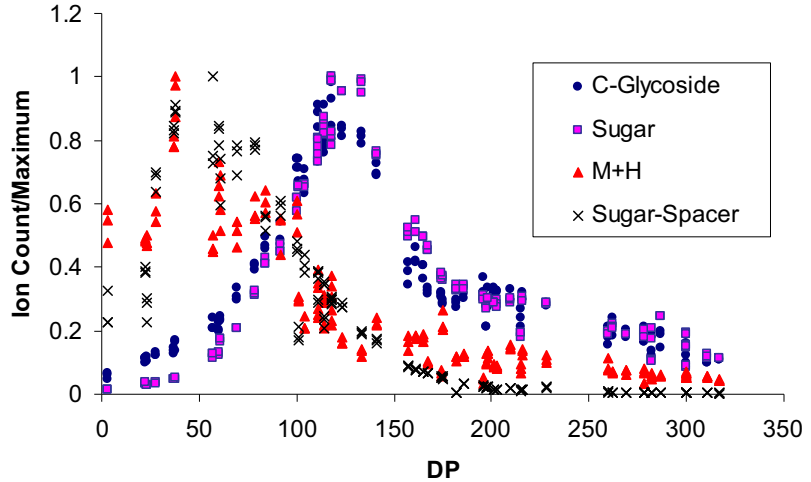

Figure 7. The influence of DP on the formation of $[\mathrm{C} \text {-glycoside }]^{+}$, $[\text { Oxonium }]^{+},[\mathrm{M}+\mathrm{H}]^{+}$, and $[(\text {Sugar-spacer })+\mathrm{H}]^{+}$ions within the ESI interface of the Q-Star Machine.

0.009), (Figure 6a) but not with the FP $(P=0.54)$ (Figure 6b). Therefore, the FP value was kept constant $(\mathrm{FP}=220)$ while studying the influence of the DP on ion formation. The pattern between the ion count (intensity) and the DP values was similar for the formation of the C-glycoside species and the sugar [oxonium] ${ }^{+}$ions (two-sample KolmogorovSmirnov test, $P=0.34$ ), but showed significant differences when the formation of the $C$ glycoside was compared to that of other ions such as $[\mathrm{M}+\mathrm{H}]^{+}$and $[(\text {Sugar-spacer-OH })+\mathrm{H}]^{+}(P$ values of $8.082 \mathrm{e}-08$ and $<2.2 \mathrm{e}-16$, respectively). As shown in Figure 7 , the $[C \text {-Glycoside }]^{+}$ion formation (with respect to DP values) followed the exact pattern of the sugar [oxonium] ${ }^{+}$species. This supports the theory that the formation of the [C-Glycoside $]^{+}$species was a product of a reaction between the sugar [oxonium] $^{+}$ion and the neutral fragment cholesta3,5-diene. Note that when comparing different species the ion count values were normalized to the maximum reading.

Table 2. List of characteristic ions observed within MS/MS analysis of protonated molecules of the neoglycolipids bearing protected sugar species

\begin{tabular}{|c|c|c|c|}
\hline Fragment ion & $4\left(\mathrm{CH}_{2} \mathrm{CH}_{2} \mathrm{O}\right)_{3}$ & $6\left(\mathrm{CH}_{2} \mathrm{CH}_{2} \mathrm{O}\right)_{4}$ & 60-glycoside \\
\hline \multirow[t]{2}{*}[\mathrm{M}+\mathrm{H}]{$^{+}$} & 1136.66 & 943.62 & 758.51 \\
\hline & $\mathrm{C}_{59} \mathrm{H}_{94} \mathrm{NO}_{20}$ & $\mathrm{C}_{51} \mathrm{H}_{84} \mathrm{NO}_{14}$ & $\mathrm{C}_{43} \mathrm{H}_{68} \mathrm{NO}_{10}$ \\
\hline \multirow{2}{*}[\text{Cholestene}]{$^{+}$} & 369.34 & - & 369.37 \\
\hline & $\mathrm{C}_{77} \mathrm{H}_{45}$ & & $\mathrm{C}_{77} \mathrm{H}_{45}$ \\
\hline \multirow[t]{2}{*}[(\text{Cholesterol-spacer-OH})+\mathrm{H}]{$^{+}$} & - & 563.47 & - \\
\hline & & $\mathrm{C}_{35} \mathrm{H}_{63} \mathrm{O}_{5}$ & \\
\hline \multirow[t]{2}{*}[(\text{Sugar-spacer-OH})+\mathrm{H}]{$^{+}$} & 768.29 & 566.25 & 390.16 \\
\hline & $\mathrm{C}_{32} \mathrm{H}_{50} \mathrm{NO}_{20}$ & $\mathrm{C}_{24} \mathrm{H}_{40} \mathrm{NO}_{14}$ & $\mathrm{C}_{16} \mathrm{H}_{24} \mathrm{NO}_{10}$ \\
\hline$[C \text {-Glycoside }]^{+}$ & - & - & - \\
\hline \multirow[t]{2}{*}{ [Oxonium $^{+}$} & 618.20 & 372.12 & 372.14 \\
\hline & $\begin{array}{c}\mathrm{C}_{26} \mathrm{H}_{36} \mathrm{NO}_{16} \\
558.18\end{array}$ & $\mathrm{C}_{16} \mathrm{H}_{22} \mathrm{NO}_{9}$ & $\begin{array}{c}\mathrm{C}_{16} \mathrm{H}_{22} \mathrm{NO}_{9} \\
312.10\end{array}$ \\
\hline [Oxonium-OAc] $^{+}$ & $\mathrm{C}_{24} \mathrm{H}_{32} \mathrm{NO}_{14}$ & & $\mathrm{C}_{14} \mathrm{H}_{18} \mathrm{NO}_{7}$ \\
\hline \multirow[t]{2}{*}[\text{Oxonium-2OAc]}]{$^{+}$} & 498.15 & 252.08 & 252.09 \\
\hline & $\mathrm{C}_{22} \mathrm{H}_{28} \mathrm{NO}_{12}$ & $\mathrm{C}_{12} \mathrm{H}_{14} \mathrm{NO}_{5}$ & $\mathrm{C}_{12} \mathrm{H}_{14} \mathrm{NO}_{5}$ \\
\hline \multirow[t]{2}{*}{ [Oxonium-3OAc] $^{+}$} & 438.09 & - & 192.07 \\
\hline & $\mathrm{C}_{20} \mathrm{H}_{24} \mathrm{NO}_{10}$ & & $\mathrm{C}_{10} \mathrm{H}_{10} \mathrm{NO}_{3}$ \\
\hline
\end{tabular}


CID-MS/MS Analysis of the Precursor Protonated Molecules of the Protected Per-O-Acetylated Neoglycolipids

We opted to choose the per-O-acetylated neoglycolipids because we anticipated that the formation of the more reactive 1,2-cyclic oxonium ion would enhance the rate of the ion-molecule reaction. This may result in more efficient formation of the $C$-glycoside in the ESI source and in the collision cell of the hybrid tandem mass spectrometer. Table 2 summarizes the fragmentation pattern of the protonated molecules $[\mathrm{M}+\mathrm{H}]^{+}$of the per-O-acetylated neoglycolipids. The presence of the diagnostic fingerprint ions: [Cholestene $]^{+},[$(sugarspacer- $\mathrm{OH})+\mathrm{H}]^{+}$, and $[\text {Oxonium }]^{+}$-was observed. Similar to the nonprotected neoglycolipids, the presence of $\left[(\right.$ cholesterol-spacer-OH $)+\mathrm{H}^{+}$was associated only with the neoglycolipid bearing $\left(\mathrm{CH}_{2} \mathrm{CHO}\right)_{4}$ spacer. As expected, the elimination products originating from the $[\text { Oxonium }]^{+}$ions were a result of one, two, or three losses of acetic acid groups (see Table 2).

The most striking finding, however, was that the $[C \text {-glycoside }]^{+}$ion was absent in the case of these per-O-acetylated sugar derivatives (see Table 2). This observation contradicts expectations based on carbohydrate chemistry foundation, given that the per-Oacetylated sugars are routinely used for $C$-glycosylation reactions in synthetic chemistry [13]. In fact, the per-Oacetylated neoglycolipids are not used for liposomal preparations and they were synthesized to enhance to formation of $C$-glycoside. However, the fact that this reaction occurs in the gas phase can introduce many new factors that are different from the conditions that rule solid and solution chemistry. One possible explanation is the overall reactivity of the per-O-acetylatedsugar oxonium ions. These oxonium ions, being extremely reactive, preferentially eliminate molecules of acetic acid and ketene, by concerted mechanisms, destabilizing the 1,2-cyclic oxazolinium ion. Therefore, this oxazolinium ion has no time to form the cyclic reactive species that can react with the electrophilic cholesta-3,5-diene molecule found in the collision cell. The CID-MS/MS of the [Oxonium] ${ }^{+}$ions that corresponds to neoglycolipids bearing the 2-N-allyloxycarbonylamino-2-deoxy group (GlcNAloc), or the per$\mathrm{O}$-acetylated GlcNAloc sugar species with the $\left(\mathrm{CH}_{2} \mathrm{CH}_{2} \mathrm{O}\right)_{4}$ spacer, were compared. The nonprotected [GlcNAloc] $^{+}$produced six fragment ions (data not shown) that are in accordance with Scheme 2 and Table 1. The protected per-O-acetylated [GlcNAloc] ${ }^{+}$ion, however, produced 15 fragment ions (data not shown). This fact supports the speculation regarding the overall reactivity of the per-O-acetylated oxonium in comparison to the nonprotected oxonium.

Although this speculation can provide some explanation for the absence of the $[\mathrm{C} \text {-glycoside }]^{+}$, other possible mechanisms such as steric hindrance cannot be excluded. Various neoglycolipids that bear glucosamine derivatives that are blocked at one or two variable positions will be synthesized and tested for the formation of the [C-Glycoside ${ }^{+}$and the outcome of this work will be the subject of a future report. Other possibilities may also unfold in the future with advances in the field of gas chemistry.

\section{Conclusions}

In this study, synthetic neoglycolipids that bear a monoor disaccharide glycosyl moiety (hydrophilic) and a cholesterol moiety (hydrophobic), which are linked by a polyethoxy spacer, were evaluated using QqToFMS/MS hybrid instrumentation (ESI and CID-MS/MS analysis). The results demonstrated clearly that, both in the ESI source and within the collision cell of the mass spectrometer, the neoglycolipids follow a universal fragmentation pattern, producing a series of product ions that corresponded precisely to the theoretical structure of these amphiphilic molecules (Scheme 2 and Table 1). Breakage can occur at either of the spacer's ends, producing most of the fragments observed in the ESI-qQ-ToF and MS/MS analysis. In addition, elimination products that are generated from the sugar portion were also observed and include product ions that are related to inner sugar fragmentation, such as the [oxonium- $\left.2 \mathrm{H}_{2} \mathrm{O}-\mathrm{CH}_{2} \mathrm{CO}\right]^{+}$ion. The genesis of these product ions was further confirmed by MS/MS analysis as shown in Figure 4. This universal fragmentation pattern can be used to easily predict the fragmentation of new compounds that have the same general structural backbone. In addition, single or multiple ion monitor reactions can be performed for any quantitative studies of liposomes bearing these novel neoglycolipids as stabilizing components.

In addition to the establishment of the mass spectrometric fingerprints of these compounds, we have shown interesting evidence for the presence of an unprecedented C-glycosylation reaction during the ESI-MS and MS/MS analysis (Figure 5 and Scheme 3). Such a reaction does not occur easily and requires reasonable efforts on a bench top in a chemistry lab. It occurred, however, in a timeframe of milliseconds within the mass spectrometry equipment. Ion-molecule reactions within mass spectrometry are old phenomena that were first noticed as early as 1913 [25]. They are mainly observed and monitored within ion trap (IT) mass analyzers (quadrupole IT and Fourier Transform MS) [26-29]. It was suggested, for example, that poly(ethylene/propylene glycol) under collisionally activated dissociation using FT-ICR MS/MS resulted in misleading rearrangements [28, 29]. Both triple- and penta-quadrupoles were also used to evaluate ionmolecule reactions [30,31]. We and others have shown that these reactions can occur under atmospheric pressure in the ESI source $[12,32]$.

In this study, a quadrupole time of flight mass spectrometer was used, illustrating the provisional occurrence of a unique C-glycosylation reaction in the collision cell as well as under atmospheric pressure in 
the ESI source. We have tentatively established that the production of a $\mathrm{C}$-glycoside occurs from a reaction between the positively charged $N$-sugar oxoniom ion and a neutral choleta-3,5-diene species. When studying these compounds in the negative ion mode (data not shown), this reaction fails to occur, supporting the mechanism presented in Scheme 3. The presence of an amino group at position $\mathrm{C}-2$ and the free $\mathrm{OH}$ groups on the C-3, C-4, and C-6 positions are both critical for the formation of this unique ion. This reaction is very distinctive because the formation of the C-glycoside is very difficult in comparison to $\mathrm{O}$ - or $\mathrm{N}$-glycosylation.

The McLafferty group has suggested that poly(ethylene/propylene glycol) under collisionally activated dissociation, using FT-ICR MS/MS or other energetic methods, inevitably issue in misleading rearrangements $[28,29]$. Brúll and collaborators reported that during MS/MS analysis of underivatized and per-O-methylated trisaccharides, with either high- or low-energy CID using FAB ionization, they observed losses of the internal residue of $1 \rightarrow 6$ substituted monosaccharide [33]. This phenomenon of "internal residue loss," which was characterized as an "internal rearrangement" process catalyzed by a proton, was not observed in the CIDMS/MS analysis of sodium-cationized oligosaccharides containing $N$-acetyl-D-glucosamine [34]. Claeys and collaborators evaluated the CID-MS/MS of $O$-flavonoid $O$-eutinosides and $O$-neohesperidosides, illustrating internal glucose residue loss. They proposed mobilization of the proton from the aglycone to the disaccharide portion [35]. Note that in the previous cases, these rearrangements reinstate the final formation of either $O$-ether or O-glycosidic linkages.

By comparison with the work of McLafferty, Brúll, and Claeys groups [28, 29, 33-35], our work, presented in this rationale, includes a series of amphiphilic molecules containing an amino sugar and cholesteryl moieties separated by a polyethylene spacer, which are indeed quite different from the products used in their respective rearrangements. Also the formation of the final compounds is not an O-glycoside but a C-Glycoside, the formation of which represents a formidable synthetic task to be achieved in a MS instrument.

We therefore cautiously propose that the mechanism of formation of the [C-Glycoside ${ }^{+}$product ion, which occurs in the collision cell of the tandem mass spectrometer, arises from the nucleophilic attack of the neutral fragment cholest-3,5-diene molecule on the activated electrophilic intermediate product [GlcNAc] ${ }^{+}$oxonium ion. We hypothesize that these latter were formed in the collision cell by fragmentation of the precursor protonated molecule. Thus, the formation of this C-glycoside occurs from the net result of breakage of two original covalent bonds separated by the polyethoxy chain spacer in the precursor protonated neoglycolipid. This $\left[\mathrm{C}\right.$-glycoside ${ }^{+}$tentatively reforms by a product ion-molecule reaction to produce a new C-1-C-3' covalent bond.

Obviously the formation of a $C$-glycoside formed by C-1-C -5 ' covalent bond is not to be excluded by the same sort of mechanism, although improbable, resulting from the more sterically hindered structure of this latter C-glycoside. Unfortunately, we do not have any chemical means to distinguish between these two possible diastereomers, or any other product that may be formed such as the most dubious C-1,2-orthoester, as the formed $C$-glycoside exists only for a fraction of a moment and cannot be isolated.

During the CID-MS/MS of the protonated neoglycolipid molecules, the $N$-acetyl-2-deoxy-D-glucosaminyl and the cholesteryl moieties are both $O$-linked and are separated by a variable-length polyethoxy spacer arm. We proposed that the formation of the C-glycoside was not related to any specific conformation in the gas phase. This was verified by molecular modeling using SYBIL 7.2.3 (SYBIL Molecular Modeling Software, Tripos, St. Louis, MO) using the Molecular Mechanic Force Field $\mathrm{MM}^{+}$under vacuum and in the same conditions mimicked from the collision cell. This showed that the lowest energy minimized structure had the hydrophilic $\mathrm{N}$-acetyl-D-glucosamine moiety very much far apart from the lipophilic cholesteryl moiety. This formation of a $\mathrm{C}-\mathrm{C}$ linkage by this type of ion-molecule reaction is quite unusual and rather unique, and could not involve, under any circumstances, a $\mathrm{C}-\mathrm{O}$ intramolecular rearrangement.

It should be also noted that most gas-phase ionmolecule reactions involve reactive atoms such as oxygen, nitrogen, and sulfur [36]. The formation of carboncarbon bonds (in nonsugar structures) were, however, observed previously; for example, Kenttamaa and Cooks [37] illustrated the formation of a characteristic cyclic product, resulting from a selective reaction between ethyl vinyl ether and hydroxycarbonyl compounds.

In summary, the exact structure and the fragmentation patterns of these synthetic neoglycolipids were tentatively established including the elucidation of a unique "in situ" C-glycosylation reaction. This fact will be further explored in the future with the aid of the state-of-the-art desorption electrospray ionization (DESI), and mass spectrometry may eventually serve as a reaction vessel that is capable of generating the final products within a very short time frame.

\section{Acknowledgment}

JB acknowledges the financial support of the Natural Sciences and Engineering Research Council of Canada in the form of a Discovery Grant.

\section{References}

1. El-Aneed, A. An Overview of Current Delivery Systems in Cancer Gene Therapy. J. Controlled Release 2004, 94, 1-14.

2. Katsube, K.; Bishop, A. T.; Friedrich, P. F. Transduction of Rabbit Saphenous Artery: A Comparison of Naked DNA, Liposome Complexes, and Adenovirus Vectors. J. Orthop. Res. 2004, 22, 1290-1295.

3. Lundstrom, K.; Boulikas, T. Viral and Non-viral Vectors in Gene Therapy: Technology Development and Clinical Trials. Technol. Cancer Res. Treat. 2003, 2, 471-86. 
4. Klibanov, A. L.; Maruyama, K.; Torchilin, V. P.; Huang, L. Amphipathic Polyethyleneglycols Effectively Prolong the Circulation Time of Liposomes. FEBS Lett. 1990, 268, 235-237.

5. Klibanov, A. L.; Maruyama, K.; Beckerleg, A. M.; Torchilin, V. P.; Huang, L. Activity of Amphipathic Poly(ethylene glycol) 5000 to Prolong the Circulation Time of Liposomes Depends on the Liposome Size and Is Unfavorable for Immunoliposome Binding to Target. Biochim. Biophys. Acta 1991, 1062, 142-148.

6. Perouzel, E.; Jorgensen, M. R.; Keller, M.; Miller, A. D. Synthesis and Formulation of Neoglycolipids for the Functionalization of Liposomes and Lipoplexes. Bioconjug. Chem. 2003, 14, 884-898.

7. Xu, Z.; Jayaseharan, J.; Marchant, R. E. Synthesis and Characterization of Oligomaltose-Grafted Lipids with Application to Liposomes. J. Colloid Interface Sci. 2002, 252, 57-65.

8. Routier, F. H.; Nikolaev, A. V.; Ferguson, M. A. The Preparation of Neoglycoconjugates Containing Inter-saccharide Phosphodiester Linkages as Potential Anti-Leishmania Vaccines. Glycoconj. J. 1999, 16, 773-780

9. Pohlentz, G.; Schlemm, S.; Klima, B.; Egge, H. Fast Atom Bombardment Mass Spectrometry of N-Acetylated Neoglycolipids of the 1-Deoxy-1Phosphatidylethanolamino-Lactitol-Type. Chem. Phys. Lipids 1994, 70, 83-94.

10. Khan, S.; Ahmad, A.; Ahmad, I. A Sensitive and Rapid Liquid Chromatography Tandem Mass Spectrometry Method for Quantitative Determination of 7-Ethyl-10-hydroxycamptothecin (SN-38) in Human Plasma Containing Liposome-based SN-38 (LE-SN38). Biomed. Chromatogr. 2003, 17, 493-499.

11. Ng, A. W.; Lukic, T.; Pritchard, P. H.; Wasan, K. M. Development and Characterization of Liposomal Disodium Ascorbyl Phytostanyl Phosphates (FM-VP4). Drug Dev. Ind. Pharm. 2004, 30, 739-758.

12. Banoub, J.; Boullanger, P.; Lafont, D.; Cohen, A.; El-Aneed, A.; Rowlands, E. In Situ Formation of C-Glycosides during Electrospray Ionization Tandem Mass Spectrometry of a Series of Synthetic Amphiphilic Cholesteryl Polyethoxy Neoglycolipids Containing N-Acetyl-Dglucosamine. J. Am. Soc. Mass Spectrom. 2005, 16, 565-570.

13. Postema, M. H. D. C-Glycoside Synthesis, 1st ed.; CRC Press: Boca Raton, FL, 1995.

14. Peri, F.; Cipolla, L.; Rescigno, M.; La Ferla, B.; Nicotra, F. Synthesis and Biological Evaluation of an Anticancer Vaccine Containing the CGlycoside Analogue of the Tn Epitope. Bioconjug. Chem. 2001, 12, 325-328.

15. Kuberan, B.; Sikkander, S. A.; Tomiyama, H.; Linhardt, R. J. Synthesis of a C-Glycoside Analogue of sTn: An HIV- and Tumor-associated Antigen. Angew. Chem. Int. Ed. Engl. 2003, 42, 2073-2075.

16. Schmieg, J.; Yang, G.; Franck, R. W.; Tsuji, M. Superior Protection against Malaria and Melanoma Metastases by a C-Glycoside Analogue of the Natural Killer T Cell Ligand alpha-Galactosylceramide. J. Exp. Med. 2003, 198, 1631-1641.

17. Boullanger, P.; Chevalier, Y.; Croizier, M. C.; Lafont, D.; Sancho, M. R. Synthesis and Surface-active Properties of Some Alkyl 2-Amino-2deoxy- $\beta$-D-glucopyranosides. Carbohydr. Res. 1995, 278, 91-101.

18. Lafont, D.; Boullanger, P.; Chierici, S.; Gelhausen, M.; Roux, B. Cholesteryl Oligoethyeneglycols as D-Glucosamine Anchors into Phospholipid Bilayers. New J. Chem. 1996, 20, 1093-1101.

19. Lafont, D.; Boullanger, P.; Carvalho, F.; Vottero, P. A Convenient Access to $\beta$-Glycosides of N-Acetyllactosamine. Carbohydr. Res. 1997, 297, 117-126.

20. Bardonnet, P. L.; Faivre, V.; Pirot, F.; Boullanger, P.; Falson, F. Cholesteryl Oligoethyleneglycol Glycosides: Fluidizing Effect of Their Em- bedment into Phospholipid Bilayers. Biochem. Biophys. Res. Commun. 2005, 329, 1186-1192.

21. Conover, W. J. Practical Nonparametric Statistics, 3rd ed.; John Wiley \& Sons: New York, 1999

22. Banoub, J.; Boullanger, P.; Lafont, D. Synthesis of Oligosaccharides of 2-Amino-2-deoxy Sugars. Chem. Rev. 1992, 92, 1167-1195.

23. Banoub, J.; El-Aneed, A.; Cohen, A.; Martin, P. Characterization of the O-4 Phosphorylated and O-5 Substituted Kdo Reducing End Group and Sequencing of the Core Oligosaccharide of Aeromonas salmonicida ssp Salmonicida Lipopolysaccharide Using Tandem Mass Spectrometry. Eur. J. Mass Spectrom. (Chichester) 2004, 10, 715-730.

24. El-Aneed, A.; Banoub, J. Elucidation of the Molecular Structure of Lipid A Isolated from Both a Rough Mutant and a Wild Strain of Aeromonas salmonicida Lipopolysaccharides Using Electrospray Ionization Quadrupole Time-of-Flight Tandem Mass Spectrometry. Rapid Commun. Mass Spectrom. 2005, 19, 1683-1695.

25. Thomson, J. J. Rays of Positive Electricity and Their Applications to Chemical Analysis. Longmans, Greens and Co.: London, 1913.

26. Wojcik, L.; Markowski, A. Mass Spectrometric Study of Ion/Molecule Reaction in Methane and Ammonia Mixtures. Vacuum. 2005, 78, 235 240 .

27. Ottens, A. K.; Arkin, C. R.; Griffin, T. P.; Palmer, P. T.; Harrison, W. W. Ion-Molecule Reactions in Quadrupole Ion Trap Mass Spectrometry: Implications for Lightweight Gas Analysis. Int. J. Mass Spectrom. 2005, 243, 31-39.

28. Vidasky, I.; Chorush, R. A.; Longevialle, P.; McLafferty, F. W. Functional Group Migration in Ionized Long-Chain Compounds. I. Am. Chem. Soc. 1994, 116, 5865-5872.

29. Cerda, B. A.; Horn, D. H. M.; Breuker, K.; McLafferty, F. W. Sequencing of Specific Copolymer Oligomers by Electron Capture-Dissociation Mass Spectrometry. J. Am. Chem. Soc. 2002, 124, 9287-9291.

30. Meurer, E. C.: Sparrapan, R.; Tomazela, D. M.; Eberlin, M. N.; Augusti, R. Cyclization Reactions of Acylium and Thioacylium Ions with Isocyanates and Isothiocyanates: Gas Phase Synthesis of 3,4-Dihydro-2,4dioxo-2H-1,3,5-Oxadiazinium Ions. J. Am. Soc. Mass Spectrom. 2005, 16, 1602-1607.

31. Chen, H.; Cooks, R. G.; Meurer, E. C.; Eberlin, M. N. Hydrogen/ Chlorine Exchange Reactions of Gaseous Carbanions. J. Am. Soc. Mass Spectrom. 2005, 16, 2045-2051.

32. Meurer, E. C.; Eberlin, M. N. The Atmospheric Pressure Meerwein Reaction. J. Mass Spectrom. 2006, 41, 470-476.

33. Brúll, L.; Heerma, W. Thomas-Oates, J. E.; Haverkamp, J.; Kovácik, V. Kovac, P. Loss of Internal $1 \rightarrow 6$ Substituted Monosaccharide Residues and Per-O-methylated Trisaccharides. J. Am. Soc. Mass Spectrom. 1997, 8 , 43-49.

34. Brull, L. P.; Kovacik, V.; Thomas-Oates, J. E.; Heerma, W.; Haverkamp, J. Sodium-Cationized Oligosaccharides Do Not Appear to Undergo "Internal Residue Loss" Rearrangement Processes on Tandem Mass Spectrometry. Rapid Commun. Mass Spectrom. 1998, 12, 1520-1532.

35. Ma, Y. L.; Vedernikova, I.; Van den Heuvel, H.; Claeys, M. Internal Glucose Residue Loss in Protonated O-Diglycosyl Flavonoids upon Low-Energy Collision-Induced Dissociation. J. Am. Soc. Mass Spectrom. 2000, 11, 136-144.

36. Eberlin, M. N. Structurally Diagnostic Ion/Molecule Reactions: Class and Functional-Group Identification by Mass Spectrometry. J. Mass Spectrom. 2006, 41, 141-156.

37. Kenttamaa, H. I.; Cooks, R. G. Identification of Protonated B-Hydroxycarbonyl Compounds by Reactive Collisions in Tandem Mass Spectrometry. J. Am. Chem. Soc. 1989, 111, 4122-4123. 